\title{
O STATUS DE "CÓPIA FIEL" DA TRADUÇÃO JURAMENTADA EM FACE ÀS DIVERSIDADES JURÍDICAS E CULTURAIS ENTRE AS LÍNGUAS
}

\section{Érika Nogueira de Andrade Stupiello}

No Brasil, a tradução juramentada é regulamentada por meio do Decreto-lei 13.609 (de 21 de outubro de 1943) e dispositivos legais posteriores que, embora visem a estabelecer um padrão de conduta para o trabalho do tradutor, não abrangem as inúmeras particularidades envolvidas na prática. Em vista das implicações legais de seu trabalho, o tradutor público parece encontrar-se em uma situação, por vezes, conflituosa, envolvendo pressupostos que, entre outras coisas, estabelecem a literalidade da tradução, sua expressa condição de cópia de um texto ou documento original, e a prática de tradução em si, que envolve, simultaneamente, diferentes línguas, culturas e, na maioria dos casos, particularidades de sistemas jurídicos diversos.

É grande a lacuna entre o que se prescreve que a tradução juramentada seja e o que o tradutor vive em sua rotina de trabalho, já que há a expectativa, por parte de clientes que contratam esse trabalho de tradução, de que o documento ou texto assim traduzido seja mais adequado, preciso e reproduza o significado exato do original. A imagem que se tem da tradução juramentada, considerando seu regime e a sua autoridade, é a de que ela seja uma representação exata do original em outra língua. Nesse contexto, a responsabilidade do tradutor juramentado reside em transpor integralmente o teor de um texto ou documento de uma língua para outra, buscando sempre manter-se imune a circunstâncias temporais, culturais e ideológicas, que possam interferir na elaboração do documento que passará a ter efeito legal no país da língua da tradução.

Este trabalho apresenta uma reflexão sobre os dois lados da tradução juramentada, sendo um deles a imagem que ela projeta, por meio dos dispositivos legais que regem a profissão e pelo rigor terminológico esperado de seu produto, e, o outro, as implicações do modo como o tradutor conduz seu trabalho e as formalidades nele envolvidas. A análise proposta abordará as diferenças jurídicas em algumas situações de tradução na forma juramentada. 
STUPIELLO - O status de "cópia fiel" da tradução juramentada...

Em um primeiro momento, será apresentado um breve histórico sobre a instituição do ofício do tradutor público no Brasil. Em seguida, tomando por base exemplos extraídos de trechos de documentos submetidos à tradução juramentada, apresenta-se uma discussão sobre o papel ativo do tradutor como produtor de significados e conciliador entre os dois sistemas jurídicos com os quais lida.

\section{Instituição e regulamentação do ofício do tradutor público e da prática de tradução juramentada}

A designação atualmente conhecida como "tradutor público e intérprete comercial" foi instituída um pouco antes do fim da Segunda Guerra, quando da publicação do Decreto 13.609, em 21 de outubro de 1943. A dupla qualificação do tradutor, desde o início, remeteu a "uma só função inseparável" (Campbell, 1983, p. 111). A tradução elaborada por esses profissionais, investida com fé pública a partir daquela data, designou-se "tradução juramentada".

Aprovados em concurso e nomeados, os tradutores públicos são considerados profissionais liberais, cujos emolumentos são estabelecidos pelas juntas comerciais dos Estados, têm autonomia para deliberar sobre as formalidades envolvidas na prática. De acordo com o senso comum, o objetivo da tradução juramentada é o de reproduzir o teor pré-estabelecido do texto ou documento original. Essa concepção da prática parece estar intimamente relacionada à noção tradicional de que o sentido estaria inscrito no texto original, e à tradução bastaria apenas retomar esse conteúdo em outra língua. Ela pressupõe também que dois sistemas possam ser intercambiáveis, tornando conveniente a ilusão de acesso a um sentido que possa ser preservado e, sem qualquer interferência, transmitido a outra cultura e a outro sistema jurídico.

Dos poucos estudos que compõem a literatura na área de juramentada, aqueles que se atêm a uma visão mais prática da profissão são os trabalhos de Campbell (1983), posteriormente, algumas publicações de Aubert (1996, 2004a, 2004b), que abordam o trabalho dos tradutores públicos no Brasil e, com uma abordagem mais generalizada, o trabalho de Asensio (2003). Há também um número especial do periódico Cadernos de Terminologia (2012) dedicado a temas da tradução juramentada. Todas as referências mencionadas seguem uma linha descritiva, na tentativa de oferecer aos tradutores públicos uma espécie de método ou orientação de como elaborar uma tradução nos moldes do que se espera para uma tradução juramentada. Um exemplo de prescrição de prática pode ser visto nas orientações oferecidas por Campbell para a elaboração da 
STUPIELLO - O status de "cópia fiel" da tradução juramentada...

tradução, segundo as quais “o Tradutor Público poderá adotar o método direto de tradução, praticamente verbum ad verbum, que proporciona maior controle dos detalhes da matéria, ou o indireto, que às vezes lhe proporciona maior desembaraço semântico e uma redação mais fluente" (Campbell, 1983, p. 117).

Campbell associa a implementação de soluções literais para a tradução juramentada como uma forma de controlar o conteúdo do texto de origem. A intervenção do tradutor estaria restrita à inserção de notas explicativas que, mesmo assim denominadas e destacadas no texto da tradução, não devem se tornar "versões pessoais, ou mesmo tendenciosas".

Aubert (1996, p. 107) atribui como característica principal da tradução juramentada a sua condição de "reprodução fiel do original (com fé pública)". Para ele, a característica de fidelidade da tradução juramentada não só faria com que o documento produzisse efeitos legais no país em que será utilizada, como também garantiria sua qualidade de "correta, precisa, exaustiva e semanticamente invariante em relação ao original".

Semelhantemente a Campbell, Aubert defende a adoção de uma abordagem mais literal na tradução de textos e documentos de forma juramentada, pois, como explica, o trabalho do tradutor público teria por prioridade a "intenção comunicativa" envolvida em seu ato de finalidade legal ou comercial. Conforme argumenta,

a expectativa de invariância semântica relativamente ao original sugere uma certa ênfase na valorização do original, uma tendência a adotar soluções literais ou quase literais, com vínculos estreitos não apenas no sentido mas, igualmente, à forma do original, mais do que buscar formas equivalentes de uso corrente na língua de chegada. (Aubert, 1996, p. 107, grifos meus)

Aubert esclarece que as "soluções literais" perseguidas pelo tradutor na tradução juramentada seriam de natureza semântica, não devendo ser entendidas como uma busca por um "paralelismo morfossintático estrito".

A expectativa, por parte de quem contrata um trabalho de tradução juramentada, de encontrar uma transcrição do original no vernáculo, faz com que o texto de origem seja valorizado em relação à tradução juramentada, levando os tradutores públicos a se fixarem ao máximo às referidas "soluções literais". Segundo Asensio,

mesmo nos casos em que o texto traduzido é valorizado como um original, sempre permanece a exigência de permitir que o texto traduzido seja comparado com o original. A busca por fidelidade ao original é uma necessidade sentida pelos destinatários das traduções (juízes, administradores). (Asensio, 2003, p. 54) ${ }^{1}$

\footnotetext{
${ }^{1}$ Esta e as demais citações em língua estrangeira foram traduzidas por mim.
} 
STUPIELLO - O status de "cópia fiel" da tradução juramentada...

Asensio reitera a necessidade de a tradução juramentada estar sempre acompanhada de seu texto de origem, uma exigência especialmente no contexto brasileiro, em que ambos os textos coexistem para fins de comparação. Já o conceito de fidelidade prende-se às palavras, aos significados e às intenções do texto de origem que, conforme defende, devem ser mantidos na tradução.

A possibilidade de ausência de interferência por parte do tradutor e de um intercâmbio incólume entre sistemas jurídicos faria parte, segundo Joseph (1995, p. 21), de um mito de que o verdadeiro autor de um texto legal seria, em si, uma entidade fictícia, "a Lei", originada com base na concepção platônica de texto legal, segundo a qual o fato de as palavras e as leis serem históricas e convencionais não as impediriam de "refletirem a forma ideal das coisas que nomeiam". Por extensão, um texto de teor jurídico revelaria sua intenção e sua tradução seria mais um reflexo perfeito desse propósito.

Joseph (1995) relaciona o desaparecimento do autor e do tradutor como a principal característica dos textos jurídicos e das traduções que deles derivam. No caso específico da tradução juramentada, seria como se a presença do tradutor só ocorresse em suas inserções parentéticas. Assim, em uma tradução jurídica, a ideia seria a de que "a única coisa que importa é a transferência exata de significado da língua original para as formulações convencionais precisas da língua alvo" (Joseph, 1995, p. 19, grifo meu).

Se, da maneira como é idealizada, uma tradução falha ao converter o significado ou estilo de um texto em um segundo em outra língua e cultura, seria porque o discurso da lei, como qualquer outro discurso, estaria sempre sujeito à interpretação e ao arbítrio tanto do autor como do tradutor. A fim de fundamentar sua reflexão sobre a tradução de textos tidos por jurídicos, Joseph (1995, p. 18) afirma que, nessas situações, "não existe uma melhor solução" e o próprio contexto em que tradutor se insere e no qual a tradução é produzida seria o fator determinante das escolhas que ele venha a fazer.

É especialmente essa concepção de Joseph que problematiza a condição de "cópia fiel", enquanto reprodução de uma origem, esperada em relação à tradução juramentada. A situação comunicacional em que o tradutor se encontra e a função que a tradução juramentada exercerá têm influência constante e decisiva nas escolhas feitas e 
STUPIELLO - O status de "cópia fiel" da tradução juramentada...

na forma como a prática é conduzida, não sendo possível restringir a prática à adoção de um único método de tradução.

Algumas das circunstâncias vivenciadas na tradução juramentada pelo tradutor são apresentadas a seguir por trechos extraídos de algumas traduções e de seus respectivos textos de origem, segundo análises de Aubert (2004a, 2004b), Asensio (2003) e Stupiello (2001). Como pretendo argumentar, as intervenções do tradutor não se restringem somente à perseguição da condição de "cópia fiel", vista como praxe de tradução juramentada, mas manifestam-se especialmente em suas soluções tradutórias, que visam a cumprir a exigência da tradução em servir como instrumento legalmente válido no país em que é utilizada.

\section{A conciliação das diferenças jurídicas e institucionais pela tradução juramentada}

Ao realizar uma tradução nos padrões exigidos para uma tradução juramentada, direcionando suas escolhas para a função que a tradução irá desempenhar, o tradutor público já está inscrevendo sua marca no texto traduzido. O uso do papel timbrado, de marcadores particulares (selos, carimbos, chancelas) e de inserções parentéticas do tradutor também constituem particularidades que distinguem uma tradução juramentada. Esses procedimentos, juntamente com os termos padronizados de abertura e fechamento de traduções juramentadas, teriam a função principal de garantir a qualidade de correção e precisão desse trabalho, além de investi-lo da autoridade que lhe é conferido pela fé pública. Além dessas funções, conforme explica Aubert (1996, p. 110), o uso desses elementos agiria no sentido de identificar a tradução como "juramentada", confirmando a expectativa de literalidade que dela se pressupõe.

Aubert (2004a) propõe uma discussão sobre o modo como os tradutores públicos interpretam o requisito da "invariância semântica" marcadamente pressuposto pelas declarações de abertura e fechamento das traduções juramentadas. Para embasar sua proposta, oferece à tradução por tradutores públicos afiliados a uma associação profissional um trecho em língua inglesa com os seguintes dizeres "I, John R. Smith, notary public duly qualified in and for the County of New Castle...". Em quatorze contribuições oferecidas pelos associados, Aubert surpreende-se com o fato de todas terem apresentado opções de tradução distintas para "uma formulação bastante invariável no idioma de partida" (Aubert, 2004a, p. 7). Entre as diversas soluções de tradução apontadas por Aubert, estão aquelas referentes aos termos "notary" e "county", 
STUPIELLO - O status de "cópia fiel" da tradução juramentada...

as quais ele classifica como culturais, e às colocações "duly qualified" e "in and for", caracterizadas como linguísticas.

As traduções de "notary" por "tabelião" ou "notário" implicam noções bastante diferentes daquela de origem, ainda que os tradutores pesquisados tenham optado por uma solução considerada mais próxima ao original com a referência a "notário". Aubert justifica a maioria das opções por "tabelião" como uma tentativa de evitar o "efeito de estranhamento cultural", mas ressalta que "o notary public americano e o tabelião público brasileiro exercem funções similares, mas de modo distinto, e com base em procedimentos de habilitação e fiscalização de suas atividades também distintos" (2004a, p. 7).

Com relação à tradução de "county" por "condado" (em vez de "distrito", "município" ou "comarca", consideradas opções funcionalmente semelhantes em nossa cultura), Aubert revela que a maioria dos tradutores empenhou-se em busca da "preservação da alteridade cultural" (2004a, p. 8). No que diz respeito às colocações "in and for" e "duly qualified" - traduzidas pela maioria por preposições coordenadas como "em e para" ou "no e pelo" e pelo adjetivo "habilitado", respectivamente - Aubert constatou parecer existir "uma espécie de equilíbrio entre a dizibilidade natural em português e a recuperação da especificidade cultural do texto em língua inglesa" (Aubert, 2004a, p. 8).

As amostras analisadas por Aubert são exemplares do constante trabalho empreendido pelo tradutor de conciliação entre sistemas jurídicos diferentes. Como o autor mesmo conclui, fundamentado no resultado de dados colhidos em uma pesquisa subsequente e publicado no mesmo periódico, o trabalho do tradutor público seria cercado de "uma certa tensão entre a busca de idiomaticidade linguística", quando o tradutor aproxima-se da cultura da tradução e "a manutenção da alteridade cultural e linguística", nos casos em que mantém a referência à cultura de origem (Aubert, 2004b, p. 8).

As duas ações resultantes da "tensão" a que Aubert se refere, não seriam passíveis de controle, delimitação precisa ou supressão pelo tradutor. Ademais, a própria constatação feita pelo autor a respeito das variadas opções de tradução revela que o trabalho do tradutor nem sempre segue um dos "métodos" sugeridos por Campbell (1983) ou adota as "soluções literais" que Aubert (1996) considera prevalecer na juramentada, mas guiam-se principalmente pelo modo como o tradutor interpreta o texto, as instituições de que ele trata e suas funções no contexto em que se inserem. 
STUPIELLO - O status de "cópia fiel" da tradução juramentada...

Essas escolhas manifestam a constante intervenção do tradutor público na tradução juramentada, assim como a conciliação do sentido entre sistemas jurídicos diferentes. Nesse caso, a fidelidade do tradutor público vincula-se ao modo como concebe sua habilitação para realizar uma tradução com efeito legal no país a que se destina. De acordo com o pensamento de cunho pós-estruturalista desenvolvido nos estudos da tradução, como nos trabalhos de Venuti (1995), Arrojo (1995) e Frota (2000), a inscrição do tradutor nos textos que lê e traduz seria inevitável, não lhe sendo possível empreender conscientemente uma escrita transparente na tentativa de encobrir sua intervenção para atender à expectativa de fidelidade atrelada a seu apagamento.

Outro exemplo do constante trabalho de recriação do tradutor público na tradução juramentada está na tradução de documentação acadêmica, em que há grandes variações entre países e, até mesmo, em diferentes estados de um mesmo país, como nos Estados Unidos. Conforme enumera Asensio (2003, p. 91), "essas diferenças afetam sistemas educacionais, autoridades, corpo docente e não docente e suas categorias, áreas de conhecimento, calendários, exames, títulos, diplomas e notas". A tradução juramentada de um documento escolar tem a função de validar ou reconhecer um curso realizado em outro país, por esse motivo, Asensio afirma que há expectativa de uma "tradução literal", e que o tradutor limite-se a "descrever fatos, deixando a interpretação para as autoridades competentes".

Por outro lado, conforme demonstra um dos exemplos de tradução oferecidos pelo mesmo autor, não é possível ao tradutor limitar-se a uma descrição imparcial dos significados que reconstrói na tradução. Um dos casos de tradução mencionado é um diploma emitido por um "Community College" nos Estados Unidos, uma instituição de ensino responsável por oferecer os dois primeiros anos de ensino superior e que não encontra referentes no sistema brasileiro. Seu caráter institucional permite que sejam outorgados aos concludentes o título de "Associate", mas não o de bacharel ou outro correspondente ao nível superior (Asensio, 2003, p. 13). Esse exemplo sinaliza que a própria diversidade no conteúdo da documentação escolar requer a intervenção do tradutor público para que suas escolhas façam sentido às "autoridades competentes", que julgarão o documento de origem pela tradução e pelo trabalho de recriação do sentido nela interpretado.

Essa situação ilustra ainda as particularidades dos sistemas escolares e a necessidade de o tradutor adequar as diferenças para que elas possam ser reconhecidas no país em que serão apresentadas como comprovantes de conclusão de uma etapa da 
STUPIELLO - O status de "cópia fiel" da tradução juramentada...

vida acadêmica do interessado. De acordo com o exemplo anterior, parece ser mais apropriada a descrição de Asensio (2003, p. 15), segundo a qual o tradutor de documentos oficiais agiria como um "comunicador entre culturas diferentes, oferecendo interpretações culturais como um auxílio para o entendimento preciso".

Ainda que a intervenção do tradutor seja concebida como marginal na tradução juramentada, todo o trabalho por ele realizado é fundamentado na sua interpretação e na construção de uma imagem do estrangeiro, com o papel de produzir sentidos e nunca de recuperá-los, já que, conforme argumenta Arrojo (1995, p. 26) "nenhum sentido se encontra presente ou imanente, mas já é sempre uma produção, qualquer ato de tradução será fatalmente uma transformação".

A ideia de transformação que a tradução juramentada produz parece gerar um efeito indesejado, de afastamento do original. Entretanto, conforme analisei em um trabalho anterior (Stupiello, 2001), o tradutor público muitas vezes cria, pela tradução, correspondências funcionais para que as particularidades de um documento estrangeiro sejam aceitas e tenham validade legal. Um exemplo pode ser tomado com base nos documentos de identificação de outorgantes e outorgados em instrumentos de procuração. Se tomarmos a tradução para a língua inglesa de documentos identificadores de pessoa física no Brasil, como "carteira de identidade" e "CPF", teremos comumente os correspondentes funcionais "identity card" e "Individual Taxpayer's Roll of the Brazilian Ministry of Finances". Se o documento de origem fosse redigido em inglês, poderíamos ter como documento identificador o "Social Security", geralmente traduzido por "Seguro Social" na tradução juramentada (Stupiello, 2001, p. 92-93).

A tradução de documentos identificadores no Brasil para o inglês constrói uma imagem da função desses documentos na cultura de origem, ao mesmo tempo em que remete a diferentes associações na cultura em que é recebida. Diferenças institucionais também podem ser observadas nas próprias definições dos termos Social Security, também chamado de social insurance de acordo com o Black's Law Dictionary (Garner, 1999, p. 807), que o define como "o seguro oferecido por um governo a pessoas que estejam passando por riscos específicos (tais como desemprego ou invalidez) ou a pessoas com um certo status (como os idosos e os deficientes visuais)". Já a designação "Seguro Social", no Brasil, diz respeito ao seguro instituído "para proteção, assistência e auxílio a pessoas menos favorecidas pela sorte, ou que vivem do trabalho, geralmente a cargo dos empregados, ou mantidos pelo Estado" (Silva, 1998, p. 743). Além da 
STUPIELLO - O status de "cópia fiel" da tradução juramentada...

significação diversa, o Seguro Social não é um documento numerado, usado para identificação pessoal, como nos Estados Unidos. Ainda que haja a intenção de reprodução do mesmo, as relações a que cada documento remete são distintas.

Esses seriam alguns dos diversos casos experimentados na rotina do tradutor público em que, ainda que as opções tradutórias sejam consideradas adequadas ou, até mesmo, "cristalizadas" para essas ocorrências, não podem ser consideradas meras reproduções do original, uma vez que cada uma constrói uma nova rede de associações na cultura para qual é traduzida. A tradução do documento "Seguro Social", por si só, remete a condições de uso para um leitor brasileiro bem diferentes daquelas construídas por um leitor norte-americano, acostumado a fornecer o número de seu Social Security em situações como à candidatura a uma vaga de emprego, entre outras. A referência ao "CPF" brasileiro como "Individual Taxpayer's Roll of the Brazilian Ministry of Finances", por sua vez, não só remete a realidades fiscais diversas, como também tem um uso como documento de identificação particular à realidade brasileira. Ocorrências como essas corroboram o argumento de que a tarefa do tradutor público envolve a construção de novos significados que, em casos como esses, oferecem uma imagem do estrangeiro.

O próprio termo "intervenção" é visto de maneira negativa por quem contrata um trabalho de tradução juramentada, preferindo-se a noção de identidade e correção, já que o resultado esperado, muitas vezes, é receber uma tradução que retrate seu texto de origem. Entretanto, conforme argumenta Obenaus (1995, p. 253), a imagem de "cópia" da tradução juramentada pode não atender às necessidades práticas, uma vez que, "embora o cliente possa solicitar uma tradução 'literal' de um contrato, isso pode não ser o que ele/ela realmente quer ou precisa". A consagrada ideia de que somente o que é literal poderá garantir a fidelidade e pureza de um texto acaba sendo, no final, a principal responsável pela tentativa de estabelecimento de prescrições e regulamentações incompatíveis com a prática.

A análise de algumas situações vivenciadas na prática de tradução juramentada levou à constatação de que, ainda que a visão tradicional de tradução a pressuponha como um trabalho exaustivo e reprodutivo de um teor já cristalizado no original, o contexto social do qual o tradutor faz parte e as condições sob as quais a tradução é por ele produzida são determinantes primeiros do produto final, isto é, o texto ou documento traduzido. Em se tratando da elaboração de documentos jurídicos em outra língua, o tradutor público não pode evitar interferir no documento que traduz e 
STUPIELLO - O status de "cópia fiel" da tradução juramentada...

transformá-lo. Por outro lado, isso não significa dizer que as transformações que realiza sejam descompromissadas ou casuais. Todas as decisões tomadas pelo tradutor em uma tradução juramentada vinculam-se às suas concepções sobre os sistemas jurídicos com os quais esteja lidando, bem como à imagem que ele projeta do papel que a tradução juramentada deverá desempenhar.

\section{Considerações finais}

Da mesma forma como é ilusória a ideia de uma transferência de conteúdos fixos, é também enganosa a noção de que o tradutor é capaz de controlar e delimitar sua intervenção e consequente visibilidade no texto traduzido. Assim, uma das concepções de fidelidade coerente com a prática seria aquela originada a partir da própria maneira como o tradutor a interpreta, isto é, a imagem que constrói da função do texto que traduz e das expectativas de seu cliente acerca de tal tradução.

A maior contribuição em se conceber a prática de tradução juramentada como uma produção de um texto ou documento por um tradutor inevitavelmente visível e atuante estaria no fato de que este, livre de pressões que não condizem com a realidade vivenciada em sua prática, estaria apto a assumir, com responsabilidade, o trabalho de produzir um texto que reflete não um original intacto, e sim uma determinada concepção e postura ética da prática.

\section{Referências}

ARROJO, Rosemary. The "death" of the author and the limits of the translator's visibility. In: SNELL-HORNBY, M. (Ed.) Translation as intercultural communication. Amsterdam: John Benjamins, 1995. p. 21-32.

ASENSIO, Roberto Mayoral. Translating Official Documents. Manchester: St. Jerome, 2003. 166p.

AUBERT, Francis Henrik. Tipologia da tradução: o caso da tradução juramentada. In: ENCONTRO NACIONAL DE TRADUTORES, 5., 1994, Salvador. Anais... São Paulo: Humanitas, 1996. p. 105-118.

Dúvidas e controvérsias: discutindo a literalidade da tradução juramentada (1). Ipsis Literis. São Paulo, n. 12, p. 7-8, 2004a.

Dúvidas e controvérsias: discutindo a literalidade da tradução juramentada (1). Ipsis Literis. São Paulo, n. 13, p. 7-8, 2004 b. 
BRASIL. Decreto-lei n. ${ }^{\circ} 13.609$, de 21 de outubro de 1943. Estabelece novo Regulamento para o ofício de Tradutor Público e Intérprete Comercial no território da República. Disponível em: http://www.planalto.gov.br/ccivil_03/decreto/1930-1949/D13609.htm. Acesso em: 4 jul. 2014.

CADERNOS DE TERMINOLOGIA. São Paulo: Citrat, 2012. Semestral. ISBN: 97885-66446-00-5. Disponível em: http://myrtus.uspnet.usp.br/tradterm/site/index.php?option=com_content\&view=a rticle\&id=1\&Itemid=2. Acesso em: 2 ago. 2014.

CAMPBELL, Armando de Salmont. Tradutores públicos e traduções juramentadas no Brasil. In: PORTINHO, W. M. (Org.). A tradução técnica e seus problemas. São Paulo: Álamo, 1983. p. 107-146.

FROTA, Maria Paula. A singularidade na escrita tradutora: linguagem e subjetividade nos estudos da tradução, na linguística e na psicanálise. Campinas: Pontes, 2000. 284p.

GARNER, Brian A. (Ed.) Black's law dictionary. 7. ed. St Paul: West Group, 1999.

JOSEPH, John E. Indeterminacy, translation and the law. In: MORRIS, M. (Ed.). Translation and the law. Amsterdam: John Benjamins, 1995. p. 13-36.

OBENAUS, Gerhard. The legal translator as information broker. In: MORRIS, M. (Ed.). Translation and the law. Amsterdam: John Benjamins, 1995. p. 247-59.

SILVA, De Plácido. Vocabulário jurídico. 15. ed. Rio de Janeiro: Companhia Editora Forense, 1998.

STUPIELLO, Érika Nogueira de Andrade. Implicações teóricas para a tradução do discurso legal. São José do Rio Preto. 2001. 197f. Dissertação (Mestrado em Linguística Aplicada) - Instituto de Biociências, Letras e Ciências Exatas, Universidade Estadual Paulista. 2001.

VENUTI, Lawrence. The translator's invisibility: a history of translation. London: Routledge, 1995. 353p. 